\title{
The model of delivering an IT product designed to activate and support senior citizens in Poland
}

\author{
Wieslawa Gryncewicz, Robert Kutera, Maja Leszczynska, Beata Butryn \\ Wroclaw University of Economics, ul. Komandorska 118-120, 53-345 Wroclaw, Poland \\ Email: \{wieslawa.gryncewicz, robert.kutera, maja.leszczynska, beata.butryn\}@ue.wroc.pl\}
}

\begin{abstract}
In the article the authors would like to find the most suitable model of delivering an IT product for elderly people designed to activate them and support their everyday activities. The article consists of a few parts. At the beginning the situation and forecasts for the population of elderly people in Poland are presented. Later the methodology of conducted research is described. In the next part the analysis of the factors influencing the activation and support of elderly people has been made. On the basis of the results of the PEST analysis key roles of stakeholders of the micro- and macroenvironment of the particular IT product are identified and their influence on the delivery model is explained. The core functions of each role are elicited and briefly described in the context of the IT product delivery model for the chosen target group.
\end{abstract}

\section{INTRODUCTION}

$\mathrm{W}$ HAT can be observed in many European societies is a demographic shift which causes significant changes in the proportion between the young and old population. The situation in Poland is very similar, however Poland, in contrast to many European countries, still seems to be a demographically young country. However, the projections for the future show a slight decrease in the total population of Polish citizens, in 2050 it will decrease by $4,5 \mathrm{~m}$, while the amount and percentage share of elderly people will increase from $21.5 \%(8,3 \mathrm{~m})$ in 2013 to $40,4 \%(13,7 \mathrm{~m})$ in 2050 [1]. This incorporates significant challenges for the Polish authorities and society itself. It is an impending threat to the economic and social stability in the country because of a great financial strain on the retirement system. As a result, the economic situation of the elderly population will get worse and they might be pushed into social exclusion.

Therefore, different parties undertake various activities to prepare for this situation. European Union funds are allocated among different $R \& D$ programs aimed at the improvement of the situation of elderly people like "Active and Assisted Living Research and Development Programme", an initiative for fostering the emergence of innovative ICT products and services, allowing seniors to live independently, in order to improve their quality of life and autonomy and reduce the cost of their care [2]. Among the Horizon 2020 programs there is also the Work
Programme 2016-2017 for Societal Challenge 1 (SC1 related to Health Demographic Change and Wellbeing) of the Horizon 2020 programme to complement, support and add value to the policies of the Member States aimed at improving the health of the EU citizens and reduce health inequalities by promoting health, encouraging innovation in health, increasing the sustainability of health systems and protecting the Union citizens from serious cross-border health threats [3]. The central government is trying to adjust the retirement system and it also organizes some funding programs, like "Government Program for Social Activity of Elderly People for years 2014-2020", whose aim is to improve the quality and level of life of elderly people in order to provide them with the possibility to age in a dignified manner through social activity [4]. There are also other initiatives organized by NGOs or private investors, like "Seniors in Action" aimed at enabling the realization of social projects by elderly people. There are many NGOs that support elderly people in their lives, some of them have national coverage, others - local. Local authorities try to support elderly people as well. They organize dedicated units to deal with matters of the elderly people, which often cooperate with NGOs, hospitals and nursing homes.

All these initiatives aimed at supporting elderly people can be supported by innovative information and communication technologies. Flexible web programming technologies, mobile devices (smartphones, tablets, wearables) with different kind of sensors (incl. health sensors) and effective wireless transmission technologies can significantly make life easier for elderly people if an IT product is customized for their needs.

At the European market, as well as at the Polish one, there are many web portals through which you can arrange a visit to a doctor or find a plumber (proreferral.com, thumbtack.com, myhammer.de, hassle.com, skilldigger.com, getdoido.com, sirlocal.pl, zamow-fachowca.pl, favore.pl, znanylekarz.pl, freelancer.pl). However, they are not dedicated to elderly people and therefore are not suited to their needs. It is important to offer seniors a solution that:

- supports them in many dimensions (providing services of different kind within a common platform), 
- stimulates their everyday activity,

- ensures proper interaction with elderly people through the interface adapted to their perceptions and needs.

The lack of such a technical solution is noticed also by different units and organizations which deal with considered target group.

Therefore the main aim of the article is to find the most suitable model of delivering an IT product for elderly people in order to activate and support them. For this purpose an analysis of the factors influencing the activation and support of elderly people has been made. It is aimed at finding key roles of stakeholders of the micro- and macroenvironment of the particular IT product as well as their core functions in the context of the IT product delivery model for the chosen target group.

\section{METHODOLOGY}

The research on activation and support of elderly people in Poland with an IT product was preceded by a wide review of scientific and professional literature, as well as of the market reports with rich statistical data. After the identification of a knowledge domain the analysis of the gathered information was made. PEST Analysis was a method chosen for that purpose. It is a tool designed to analyse macro environmental factors [5]. The factors are classified into four different categories which cover political, economic, technological and social factors. As a result, there could be defined an environmental context of the issues analysed and the directions of micro environmental changes. Such an analysis is most frequently used to specify essential environmental sectors which influence a particular organization and its operating strategy [6] [7].

The purpose of the analysis resulting from a thorough understanding of the socio-political, economic and technological context was to identify the key characteristics of the IT product designed to activate and support this social group. They covered such factors as: the living standards of elderly people in Poland, their digital competencies and the infrastructural conditions.

The application of PEST tool resulted in the preliminary verification of the Polish market potential for the IT product dedicated to elderly people. It also allows to define the general profile of an IT product which may, after its adjustment to specific macroeconomic conditions, respond to the needs and expectations of the prospective recipient. The examination procedure involved the following steps:

1) Specifying through brainstorming the most significant factors to be taken into account in PEST Analysis, namely political, economic, social and technological factors.

2) Verification of the available research reports, including the statistical ones, and of the available resources in order to carry out a detailed analysis of the factors and in order to specify their impact and likelihood.

3) Specifying the influence of the factors on the IT product profile by defining the characteristics thereof.
The results of the analysis were later utilized for defining the model of the IT product delivery. For the graphical representation an onion model was chosen. It is a graphbased diagram template, which can be useful for understanding the interrelationships between an IT product and its stakeholders from micro- and macroenvironment [8][9]. Its structure can reflect the complexity of the model and strength of impact of particular roles of stakeholders by placing them on the proper layer. The first step in building the model was to develop a list of the potential roles of the stakeholders. Then the roles were assigned to the proper layers of the model: micro- or macroenvironment of the IT product. At the end, the core functions of each role were defined, analyzed and described.

\section{PEST ANALYSIS - CONCLUSIONS AND REMARKS FOR AN IT PRODUCT}

The Authors evaluated the factors which had been selected at the first stage of PEST Analysis by specifying their impact (on a scale from -2 to 2 , where -2 was means factors with a very negative impact, +2 means factors with a very positive impact and 0 means factors of a neutral character) and likelihood (on a scale from 0 to 1 , where 0 means unlikely phenomena and 1 means phenomena certain to happen). The influence was evaluated by multiplying one of the aforementioned factors by another. The detailed description of the whole studies and their results were presented during EHST conference last year [10].

Furthermore, the Authors determined in discussion the characteristics of the IT product dedicated to elderly people. The said characteristics constitute a response to a given factor and if the factor is negative, they constitute an antidote which is capable of eliminating its influence. At this stage, it is also possible to notice that according to the Authors, what influences the IT product dedicated to elderly people in the strongest, positive way is a high level of informatisation in Poland and what has the most negative influence are the biological, psychological and social barriers in the IT perception related to aging. The summary of the PEST Analysis effects is presented in Table 1.

On the basis of PEST Analysis, the Authors observed that what has the strongest positive influence on such a product is a high level of informatisation in Poland. Due to the existence of a developed infrastructure and due to the falling costs of its use, elderly people have a better access to modern IT products and to the Internet. Furthermore, both the domestic and European policies support initiatives dedicated to the analysed social group by providing the source of financing. Thus, IT companies have a possibility to provide senior citizens with a free access to their products and services. At the same time, the Software-as-a-service (SaaS) model is gaining importance as a form of software delivery. In that model the entire infrastructure along with the software is under the control of the service provider, while the user retains control over his or her data [11]. 
TABLE 1 PEST ANALYSIS RESULTS

\begin{tabular}{|c|c|c|c|c|}
\hline Factor & $\begin{array}{l}\text { Impact } \\
\text { (from }-2 \\
\text { to } 2 \text { ) } \\
\end{array}$ & $\begin{array}{l}\text { Likelihood } \\
\text { (from } 0 \text { to } 1 \text { ) }\end{array}$ & $\begin{array}{l}\text { Influence } \\
\text { (impact x } \\
\text { likelihood) } \\
\end{array}$ & IT product expected characteristics \\
\hline \multicolumn{5}{|c|}{ Political factors } \\
\hline $\begin{array}{c}\text { European and domestic policies } \\
\text { facilitating activation of senior } \\
\text { citizens }\end{array}$ & +2 & 0,5 & 1 & Free \\
\hline Domestic legal framework & -1 & 1 & -1 & Compliant with the legal framework \\
\hline Prolonging working life & 1,8 & 0,6 & 1,08 & $\begin{array}{c}\text { Oriented at offering services and } \\
\text { entering into transactions }\end{array}$ \\
\hline \multicolumn{5}{|c|}{ Economic factors } \\
\hline Structure of income/expenses & -1 & 0,7 & $-0,7$ & Free \\
\hline Level of wealth & 1,2 & 0,5 & 0,6 & Free \\
\hline \multicolumn{5}{|c|}{ Social factors } \\
\hline $\begin{array}{l}\text { Age-related biological, mental, } \\
\text { social barriers in IT perception }\end{array}$ & $-1,6$ & 0,8 & $-1,28$ & $\begin{array}{c}\text { Adjusted to elderly people's perception } \\
\text { Help desk support provided }\end{array}$ \\
\hline Social mobility & 1,4 & 0,3 & 0,42 & $\begin{array}{c}\text { Community oriented (relations and } \\
\text { communication) } \\
\text { Mobile } \\
\text { Integrated with popular messengers } \\
\end{array}$ \\
\hline \multicolumn{5}{|c|}{ Technological factors } \\
\hline Informatisation level in Poland & 2 & 1 & 2 & Available online \\
\hline $\begin{array}{l}\text { Level of acceptance of technology } \\
\text { by citizens }\end{array}$ & $-1,8$ & 0,3 & $-0,54$ & Help desk support provided \\
\hline $\begin{array}{l}\text { Condition of telecommunication } \\
\text { market in Poland }\end{array}$ & 0,6 & 0,9 & 0,54 & $\begin{array}{l}\text { Using popular communication channels } \\
\text { (text messages, e-mail) }\end{array}$ \\
\hline Software provision method & 1,5 & 0,7 & 1,05 & Available in SaaS model \\
\hline Easiness of software developing & 0,4 & 0,9 & 0,36 & $\begin{array}{l}\text { Using web standards } \\
\text { Open to integration }\end{array}$ \\
\hline Technological progress & 0,6 & 0,7 & 0,42 & Easily expandable \\
\hline
\end{tabular}

At the same time negative influences of several factors of the analysed environment were observed. While creating the profile of the IT product dedicated to elderly people one should take into consideration biological, psychological, social and legal barriers which constitute an obstacle for the users in question. Therefore, it is important to create suitable IT products which will respond to the needs and perception of elderly people and to undertake measures designed to educate them in this field. This will allow senior citizens to benefit from their intellectual capital, experiences and skills. Furthermore, this will help to eliminate the generation gap as well as the digital exclusion of elderly people.

\section{THE IDENTIFICATION OF THE CORE STAKEHOLDERS' ROLES AND THEIR FUNCTIONS IN THE IT PRODUCT DELIVERY MODEL}

What was identified at the first stage of research on the IT product delivery model dedicated to elderly people was the role which might be performed by the stakeholders functioning in the product's environment. The aforementioned roles are graphically presented in Fig. 1. It should be emphasised that the presented model does not exclude either the situation in which different roles are performed by different stakeholders or the situation in which one stakeholder performs distinct roles.

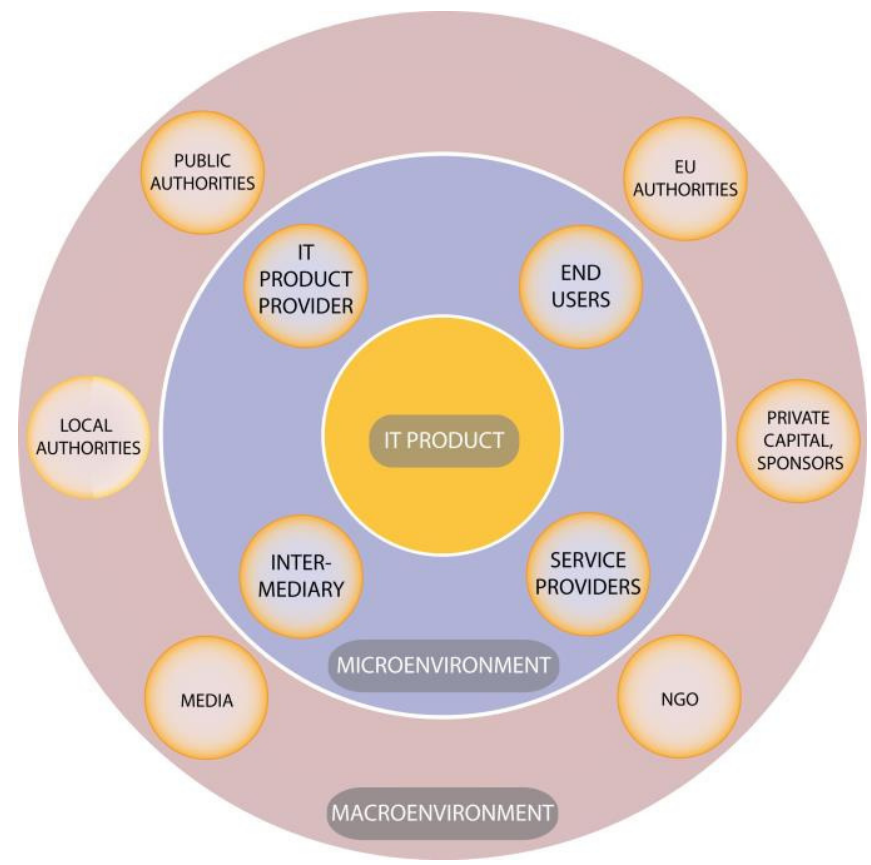

Fig. 1. Key roles of the stakeholders of IT product in the context of its delivery model for elderly people

Furthermore, the model demonstrates the roles of stakeholders from microenvironment, which directly interact with the product. Additionally, it presents the roles of stakeholders from macroenvironment, which interact with 
the product in an indirect manner and which create the context and environment where both the product and the stakeholders from microenvironment function. In order to present the IT product delivery model dedicated to elderly people the Authors used the Onion Model, whose layers allowed them to clearly demonstrate and analyse the elements of the micro- and macroenvironment [10].

The roles of stakeholders are the following:

- End users - senior citizens,

- Service providers - entities offering services and products to senior citizens,

- IT product provider - the entity responsible for the IT product development, its delivery to the other stakeholders and technological support,

- Intermediary - the entity which mediates between senior citizens, service providers, and the IT product provider.
The roles of stakeholders from macroenvironment are the following:

- EU authorities,

- Public authorities

- Local authorities,

- Private capital, sponsors,

- Public benefit organisations - NGO,

- Media.

As it has already been indicated above, the stakeholders from macroenvironment are those which create the environment where the other elements of the model can function. The said environment can be understood as the legal regulations which shape not only the social and economic conditions but also available ways of financing innovative solutions for senior citizens (private and public capital), bringing senior citizens together and activating them.

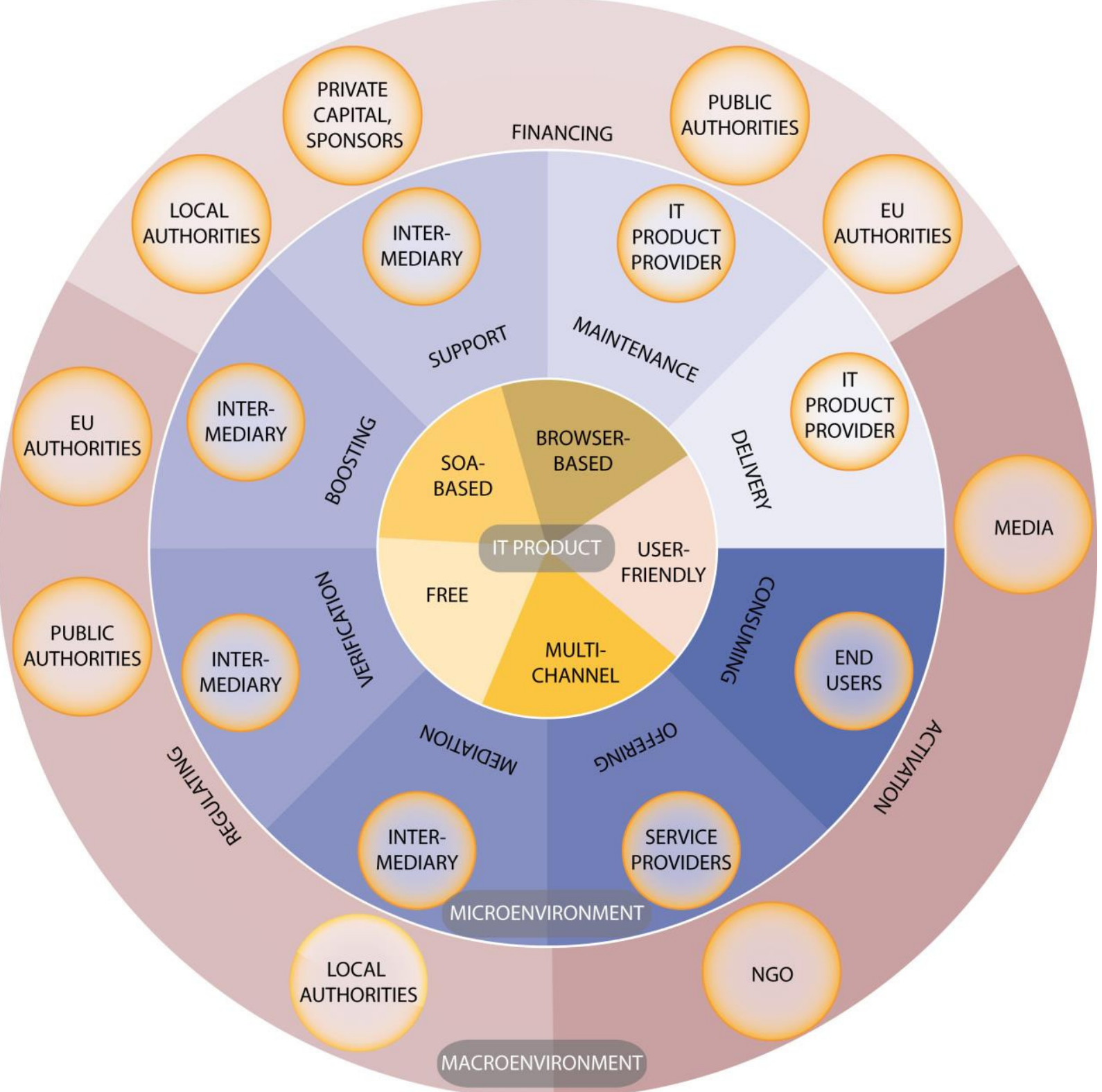

Fig. 2. IT product delivery model for activating and supporting elderly people 
The next step in the research on the presented model was to define the characteristics of the IT product itself as well as to indicate the functions performed by particular roles located in the respective layers of the model. Owing to this, it was possible to present the model of a comprehensive character, which ultimately covered the product characteristics, roles performed by particular stakeholders and their functions. This has been illustrated in Fig. 2. It should be noted that the presented model of the IT product delivery has been developed on the basis of the PEST analysis results. Its elements have been defined in such a way that they constitute a response to the factors selected during the analysis and if the factor is negative, they constitute an antidote which is capable of eliminating its influence.

Among the characteristics defining the shape of the IT product the Authors indicated the following:

- The product being available to senior citizens for free,

- The product being available in the SOA model,

- The product being available through the browser without the necessity to install it,

- The interface being unified for all the offered services and featuring improvements dedicated to senior citizens,

- Multichannel - the IT product ability to work with different communication channels.

The fact that the product should be made available to senior citizens for free responds to this factor selected in PEST analysis which indicates that elderly people in Poland have low incomes and therefore they will refuse to pay for the usage of an application of any kind. Another factor selected for the purpose of PEST analysis which has an influence on the IT product characteristics is the one related to the low level of digital competences among senior citizens. What has been suggested in order to eliminate this factor is the solution in which it will be possible to use the IT product without the necessity to install it. The aforementioned solution will be available due to the fact that the product will be built in compliance with the SOA (Service-Oriented Architecture) principleswhat ultimately will make it available as a service from the browser level. In practice, this allows to access the functionalities of the product and its interfaces just after entering the proper web page address into a web browser. The unified interface featuring improvements dedicated to senior citizens constitutes, in turn, the response to the barriers related to the limited perception of IT solutions, which results from biological and mental aging. Multichannel, which provides an access to different communication channels, shall enable efficient communication between both senior citizens and service providers and among senior citizens themselves. It is worthwhile to mention that the channels should be selected according to the criterion of usefulness for the target group. PEST analysis indicates that among the web technologies, senior citizens most frequently choose voice messengers (e.g. skype).

The next stage of building the IT product delivery model designed to support senior citizens' independence in life consisted in defining the functions which are performed by the particular roles. They shall be characterised below.

The term "end users" should be understood in this model as senior citizens who use the IT product to order those services which will allow them to live self-reliant, independent lives. Therefore, they perform the "consuming" function in this model. In this function they register and then $\log$ into the IT product, thus gaining the access to their profile, to service providers' offers and to the mechanisms of ordering, appointment coordination and service quality evaluation. The interface available is unified and its appearance has been tailored to the needs of senior citizens. It becomes their single point of contact and allows them not only to order and evaluate services, which give them independence in life, but also to form a community within which they communicate with their peers. In case of any problems with the "consuming" function, senior citizens can ask the intermediary for help, what shall be depicted further in this article.

Service providers constitute another party to transactions realised with the usage of the IT product, and, as the term itself indicates, they provide services to senior citizens, thus performing the "offering" function in this model. In this function they specify their service offers, manage their own time or the time of their employees and/or volunteers, provide end users with the ability to book services, manage price lists and discounts, customise offers and confirm that the service will be performed.

IT product providers, in turn, have been assigned two basic functions in the presented model:

- Delivery,

- Maintenance.

The said functions are performed through developing the IT product in a particular programming language and through ensuring its broadly understood maintenance, covering not only the correction of errors but also product development and technological support for the users. The activities related to the $1^{\text {st }}$ line technological support are conducted via the intermediary in this model. The aforementioned solution is applied in order to overcome the selected for PEST analysis barriers resulting from senior citizens' low digital competences and their problems with the perception of IT products. Furthermore, it should be noted that the "delivery" function is performed by the provider through delivering the IT product in the form of a service in the SaaS model. In practice, this means that the IT product, developed in compliance with the SOA principles is available via a browser, without the necessity to install client software. This responds to senior citizens' low digital competences, which were diagnosed with the application of 
PEST analysis, and which manifest themselves in their lack of skills at computer administration, among other things.

The intermediary, in turn, has been assigned the following functions:

- Support,

- Mediation,

- Verification,

- Stimulation.

The intermediary is a stakeholder whose task is to respond to such factors selected in PEST analysis as: age-related mental, biological and social barriers in the perception of the IT product, senior citizens' low digital competences, distrust in new IT solutions and in service providers. The "support" function is performed by the intermediary through two basic activities:

- Providing a help-desk which offers ongoing technological and substantive assistance to senior citizens,

- Ensuring trainings for senior citizens, volunteers, and service providers.

The "mediation" function covers the relation between:

- Senior citizens, service providers and the IT provider, not only in the field of solving current problems but also of defining the needs which should be reflected in the IT product (functional analysis),

- Senior citizens and service providers in the area of financial transactions (negotiating the price, settlements of transactions) and of ordering the services on behalf of senior citizens (helpline)

The function designed to verify the quality offered by service providers covers both the preliminary assessment of their reliability before they are admitted to offer their services in the platform and the confirmation of the correctness of the services performed for senior citizens. With the usage of these tools, the intermediary builds broadly understood confidence in ordering services in this way.

The "stimulation" function, in turn, can be analysed in the context of cooperation with both senior citizens and service providers. The intermediary not only maintains contact with organizations whose task is to activate senior citizens and to bring them together, which is his way of attracting new end users, but he also actively searches for and attracts service providers which intend to reach senior citizens with their offer with the usage of the IT product. The intermediary can also attract individual volunteers who are interested in providing elderly people with their assistance. Furthermore, the intermediary stimulates senior citizens to communicate with one another within the IT product and to exchange opinions about service providers, thus enabling the users to form an active community.

The introduction of the intermediary, whose task is to organise broadly understood assistance for senior citizens, to actively stimulate them to use the IT product, to satisfy their everyday needs, to verify the quality of services and to supervise financial transactions, allows to promulgate the concept of the IT product among senior citizens and, first of all, to build trust in it. This is the way in which the barriers resulting from senior citizens' low digital competences and their distrust in technological and process innovations are overcome. What is also eliminated owing to the existence of the intermediary is the problem of dishonest service providers, which are monitored by the intermediary and end users (senior citizens) on an ongoing basis. While performing these organic functions, the intermediary can apply different communication channels offered by the IT product.

Basic functions performed by the stakeholders from macroenvironment are the following:

- To provide financial means applicable to create new IT solutions dedicated to senior citizens,

- To undertake measures to activate senior citizens to use such technological solutions,

- To amend legal regulations in an ongoing manner in order to adjust them to the changing social needs.

Current measures undertaken by the local, public and EU authorities support financially technological innovations designed to provide senior citizens with the means which will enable them to live independent lives. The examples of such initiatives have already been discussed in the Introduction. Owing to such programmes, the organisers of such social initiatives can obtain financing, and, consequently, they can offer their IT products for free. This is particularly important in Poland. The research conducted earlier clearly indicates that Polish senior citizens are reluctant to pay for the usage of applications due to their low incomes.

What also constitutes a significant source of financing of activities related to providing senior citizens with technological solutions is private sponsoring. Companies (State-owned companies or private companies) donate funds for such purposes according to the assumptions on the corporate social responsibility (CSR). The fact that companies participate in the life of the local community and that they engage themselves in social investments constitutes the root of their firm position in this community. Not only do they gain the hearts of the local population but also the trust of the local authorities.

It is also possible (at the early stage of the project) to obtain financing from venture capitals, which will receive their shares in such a project.

Private individuals also support such initiatives through small one-time donations (crowdfunding) made via such crowdfunding platforms as Kickstarter or PolakPotrafi.pl. By doing so, they express their support for such projects and they even receive some petty benefits (e.g. shares in the project, discounts for services, gadgets, etc.)

Activating elderly people in the context analysed in this article takes place through informing the target group about 
the possibilities to take advantage of such applications. This might be done through organising different social events, workshops, lectures, trips etc. What should be presented during such meetings is the system itself together with its characteristics, possibilities, and basic functionalities. It is also important to promote an active lifestyle suitable for senior citizens and to show them paths of their prospective development (third age universities). Due to such measures, they will be more willing to benefit from different kinds of services ant it will be easier to persuade them to use the system described in this article.

This is the role performed mostly by NGOs and the media. Such actions should be also taken by care institutions, hospitals, church organisations and public figures. Due to their authority they will be able to recommend using such applications. What should also be promoted and rewarded are different forms of volunteering aimed at raising the awareness of senior citizens in the area of ordering services via the discussed system.

The Authors indicate legislative works, especially drafting legal provisions (both national and European regulations) as the third function performed by the stakeholders from macroenvironment of the IT product. The role of the said regulations is:

- To guarantee the security of transactions realised via the Internet,

- To protect personal data,

- To enable providers to offer services for elderly people in volunteering,

- To allow elderly people to work without losing their retirement pensions,

- To enable elderly people to offer mutual services (via the so called "time banks") and to settle their accounts (payments received for the work done) with the usage of virtual currency or barter.

The roles listed above and their functions constitute the basic structure of the model, yet, the possibility of its further extension or modification in non-standard cases is not excluded. The local or public authorities, for example, might perform the function consisting in activating elderly people even though the said function has been originally assigned only to the media and NGOs. Similarly, not only the intermediary but also service providers can boost the movement on the IT product web page through organising various promotional campaigns on their own web pages or during personal meetings with their clients.

\section{IV.CONCLUSIONS AND FURTHER RESEARCH}

The article presents the IT product delivery model dedicated to activate and support senior citizens in their independent everyday lives. The model has been developed on the basis of the strategic PEST analysis. The roles defined in this model and the functions performed by them constitute the response to the factors selected in PEST analysis and are designed to indicate the most important elements of the efficient delivery of the IT product which is suitable for the needs of the analysed target group. The Authors have also specified the strength of impact which particular roles and functions have by locating them in the proper layers of the onion model.

On the basis of the conducted research the following conclusions have been formulated:

- The presented model is of a comprehensive character and it covers such elements as the product, roles performed by particular stakeholders from microand macroenvironment and their functions,

- The elements of the model have been defined in such a way that they constitute a response to the factors selected during PEST analysis and if the factor is negative, they constitute an antidote which is capable of eliminating its influence,

- Particular roles have different strength/form of impact - they can influence the IT product interacting with it directly (delivery, maintenance, consuming/offering) or indirectly through creating favourable conditions for the usage of such solutions,

- Among the indicated roles which interact directly with the product, the role of the intermediary has been emphasised as he mediates between senior citizens and the other roles in the model and he facilitates senior citizens' usage of the IT product (eliminating age-related mental, biological and social barriers),

- The application of the suggested IT product delivery model constitutes an opportunity to reach the target group in the most efficient manner and to eliminate their individual limitations as well as the limitations resulting from the environment as identified in PEST analysis.

The research presented in this article does not cover all of the issues related to delivering IT products designed to increase the senior citizens' quality of life. On the one hand, what seems to be of particular importance is to deepen the analysis of all the stakeholders engaged in the process of the IT product delivery to the market, but on the other, the Authors acknowledge the need to model the functional structure of the product itself. Future papers authored by the research team shall be devoted to the aforementioned problems.

\section{REFERENCES}

[1] GUS, Prognoza ludności na lata 2014-2050, Studia $i$ analizy statystyczne, 2014, Retrieved April 9, 2016, from: https://www.mpips.gov.pl.

[2] Active and Assisted Living Programme, Retrieved April 9, 2016, from: http://www.aal-europe.eu

[3] The Consumers, Health, Agriculture and Food Executive Agency, Call 2016, Retrieved April 9, 2016, from 
http://ec.europa.eu/chafea/documents/health/hp-pj-2016-call-text_en.pdf [4] MPiPS, Rzadowy Program na rzecz Aktywności Społecznej Osób Starszych na lata 2014-2020, Retrieved April 9, 2016, from: https://www.mpips.gov.pl.

[5] Mindtools, PEST Analysis. Identifying "Big Picture" Opportunities and Threats, Retrieved April 9, 2016, from: http://www.mindtools.com.

[6] R.B. Duncan, Characteristics of organizational environments and perceived environmental uncertainty. Administrative Science Quarterly 17(3), 1972.

[7] D. Ward, E. Rivani, An Overview of Strategy Development Models and the Ward-Rivani Model, Economics Working Papers, 2005.

[8] K. Siau, R. Chiang, B. C. Hardgrave, Systems Analysis and Design: People, Processes, and Projects, Routledge, 2015, p.61
[9] M. E. Porter, Competitive Strategy: Techniques for Analyzing Industries and Competitors, 1st Edition, The Free Press, New York 1998

[10] B. Butryn, W. Gryncewicz, R. Kutera, M. Leszczyńska "The Application of PEST Analysis to the Creation of the Profile of an IT Product Designed to Activate and Support Senior Citizens in Poland", in Proceedings of 9th International Symposium on e-Health Services and Technologies (EHST 2015), Rhodes; 09/2015, pp. 109-115.

[11] D. Jelonek, C. Stępniak, T. Turek and L. Ziora, "Identification of mental barriers in the implementation of cloud computing in the SMEs in Poland," Computer Science and Information Systems (FedCSIS), 2014 Federated Conference on, Warsaw, 2014, pp. 1251-1258. 